\title{
Seth Lindstromberg 2010. English Prepositions Explained. Rev. ed. Amsterdam/Phila- delphia: John Benjamins Publishing Company. 273 pages. ISBN 978-90-272-1174-3
}

As Diane Larsen-Freeman observes in one of the recommendations on the back cover of this book, "Prepositions are notoriously difficult to learn .. and to teach". It is therefore admirable that someone has taken upon himself to give a coherent account of the meaning(s) of the most frequently used English prepositions.

The book falls into six parts: The most important of these is part three (Chapters 2-20, pp. 29-242), in which Lindstromberg presents the data concerning prepostional meaning. In part two (Chapter 1, pp. 1-28) we are given an introduction and orientation to matters such as justification for the book, types of prepositional meaning, types of classification of prepostions, idioms with prepositions, etc. The remaining four parts consist of auxiliary chapters and sections. Part one is a list of symbols, abbreviations and features of format, while part four (Chapter 21, pp. 243-262) gives a survey of important abstract notions expressed by prepositions. Part five (pp. 268-270) and part six, (pp. 268-270) are a glossary of terms used in the book and a general index including the prepositions dealt with in the book, respectively

Section 1.1 specifies the intended readership as follows:

- teachers of English

- translators and interpreters in training

- undergraduates in English linguistics programs

- studious advanced learners and users of English

- EFL/ESL materials writers

- anyone who is inquisitive about the English language.

This is a rather wide-ranging readership in terms of the ways in which each readership group might expect the book to assist them in meeting information needs. I shall return to this question at the end of the review.

Section 1.2 justifies the book by claiming that grammar handbooks are mainly about grammar, not meaning, and that dictionaries order their entries alphabetically, which means that information about particular prepositions can be difficult to find. While it is true that most reference grammars do not cover prepositional meaning, there are exceptions. Quirk et al. (1985) devote no less than 40 pages (pp. 673-713) to prepositional meanings, while Leech \& Svartvik (2002) treat prepositional meanings (together with meanings of adverbs and conjunctions) under notional headings such as time, place (including abstract place meanings), manner, means, etc. etc. With respect to dictionaries, it is of course true that "information about prepositions is scattered across hundreds or even thousands of pages" (p. 1), but a few attempts have been made to compile specialised dictionaries covering only prepositions such as for example Schwarz (2007), a bilingual DanishEnglish dictionary.

Section 1.3 gives an overview of the prepositions covered in the book, while section 1.4 explains why some prepositions are not covered in the book. Section 1.5 lists the corpora from which examples have been collected.

In Section 1.6, Lindstromberg states that the meanings and usages of prepositions given in chapters 2-20 are those that are "widely shared" (p. 4) by native speakers of English and Section 1.7 explains the role prepositions play in (strong) collocations and fixed expressions.

The function of the typical preposition is to relate two entities to each other such as locating physical objects in relation to each other as for example in 'There is a candle on the table'. Section 1.8 provides terms for these two entities, namely Subject for the entity ( $a$ candle) whose location the speaker wants to indicate, and Landmark for the entity (the table), in relation to which the 
Subject is located.

Sections 1.9-1.12 make a number of distinctions related to prepositional meaning such as that between the meaning of a preposition (what is in the mind of the speaker) and the form of a preposition (spelling and pronunciation) (Section 1.9), that between meanings (big differences in meaning) and senses (small differences in meaning) (Section 1.10), that between the literal, spatial meanings of prepositions on the one hand and the abstract, figurative usages of prepositions on the other hand (Section 1.11) and finally that between geometrical meaning and functional meaning (Section 1.12).

To help understand prepositional meanings, chapters 2-20 feature a number of icons, which are explained in Section 1.13.

Section 1.14 is devoted to a large number of classifications of prepositions from the more trivial ones such as classification by number of syllables over classification by frequency, by register (level of formality), by source language etc. to the perhaps more controversial classification by transitivity. Normally, transitivity refers only to complementation of verbs. It is claimed that the preposition 'in' in 'Let's go in the house' is transitive, while in 'Let's go in', it is intransitive. More controversially, it is claimed that 'away' in 'Go away' is an intransitive preposition. While some standard grammars such as Quirk et al. (1985:713) recognizes that 'in' in 'Let's go in' is in some way related to the preposition 'in', they prefer the term 'prepositional adverb', but no standard grammar can see any 'prepositionhood' at all in the word 'away' in 'Go away'. However, by including what standard grammars would classify as adverbs, Lindstromberg can cover a large number of expressions, whose meanings are related to the meanings of prepositions. It should also be added here that in Section 1.18, Lindstromberg attempts to justify why the term 'preposition' is used in such a way as to include not only what some would call 'directional adverbs' ('away' in 'Go away'), but also particles such as 'over' in 'I turned the book over'.

It should be noted here that Lindstromberg does not mention at this point that a section in Chapter 20 treats what standard grammars call the infinitive marker 'to' as in for example 'I want to succeed' as if it were a preposition. There may be some justification for claiming that the to-infinitive in 'I want to succeed' represents some kind of prepositional meaning (abstract destination), but it would be advisable to mention that 'prepositionhood' can only be claimed for the infinitive marker 'to' on purely semantic grounds.

Section 1.15 returns to prepositional meaning distinctions, discarding a two-way distinction. well-known from cognitive linguistics, between prototypical meaning and secondary/extended meaning in preference to a three-way distinction between basic meaning ('basic for pedagogical purposes'), secondary literal meanings and noteworthy figurative and/or abstract usages. Presumably, 'basic for pedagogical purposes' refers to the meanings that seem to be most easy to teach learners of English, although this is not explicitly stated. Furthermore, it also seems as if 'basic meanings' also refers here to meanings that are "possibly also conceptually basic in the minds of many native speakers" (p. 21). The notion of 'secondary literal meaning' is not defined at this point, and there is no assistance to be found in the glossary, where we are given only a definition of 'literal meaning':

'literal meaning In general, the literal meanings of a spatial preposition are the meanings which are applied in the description of physical scenes and scenarios. There are other posibilities, however. For example, the literal meaning of UNTIL concerns time, while the literal meaning of CONCERNING has to do with marking the Landmark as a topic.' (p. 269).

Furthermore, the notion is very rarely referred to in chapters 2-20, one example being (perhaps) in Chapter 3: ' $\mathrm{ON}^{2}$, which is approximately the opposite of $\mathrm{BACK}$, is primarily about movement and secondarily about orientation.' (p. 53, my emphasis).

Section 1.16 and 1.17 look at phrasal verbs (including prepositional verbs and phrasal-prepositional verbs), particularly (in Section 1.17) at the distinction between phrasal verbs with a generic 
verb (such as 'get', 'give', 'put' etc) with a transitive or intransitive preposition on the one hand and so-called 'perfective' phrasal verbs (also called 'aspectual phrasal verbs', see for eample Darwin \& Gray (1999)), which consist of a relatively non-generic verb (such as 'cut', 'close', 'die', etc.) in combination with an intransitive preposition which indicates that the action or transition of the verb is definite and/or thorough. The former are judged to be much more difficult for learners of English and therefore subject to frequent dictionary consultations, whereas the latter - because of their relative regularity - are much easier to learn.

Section 1.19 discusses the guessability of the meanings of idioms that include prepositions. Lindstromberg admits that it is not always the prepositional element of an idiom that is solely responsible for its idiomaticity; other elements (such as the verb in a phrasal verb) may share this responsibility, but since the book is about prepositional meaning, one of the central aims is "to help both learners and teachers of English to become more successful in using a knowledge of prepositions as a key for 'unlocking' the meanings of idioms in which prepositions occur” (p. 26). It is an ambitious objective, but on the whole, Lindstromberg achieves what he sets out to do in this respect.

Section 1.20 tries to explain why we can use the sentence 'The chair is under the table' to describe a situation, in which the chair is not fully underneath the table, but where it is in its normal position alongside, but partly under the table (in fact with some of the back of the chair above the table). The explanation is functional: The sentence describes the position of the elements that matter, particularly the chair-seat, which is partly or fully under the table. Since the section does not offer any explanation as to how this account relates to the data on prepositional meaning in chapters 2-20, it is difficult to see its relevance.

The final section of Chapter 1 lists the major non-spatial notions expressed by prepositions and refers to Chapter 21, where these abstract notions are more fully described.

There is no doubt that Chapters 2-20 provide the reader with a very deep insight into the meanings/senses of the most frequently used English prepositions. Each chapter is also well organised, starting with the most basic (very often spatial-concrete) meanings of the prepositions covered in the chapter and proceeding to figurative/abstract meanings. These figurative/abstract meanings are further treated in Chapter 21, where they are listed under alphabetically ordered notions such as 'Addition', 'Agent', 'Correspondence', 'Opposition', 'Possession', etc. etc. The book may thus be conceived of as a catalogue of prepositional meaning in English. By reading the book 'from cover to cover', so to speak, users of the book will get an excellent global overview of prepositional meaning in English. Although this is not explicitly stated, this is presumably how the author intended the book to be used.

However, it is an open questions whether all the groups of targeted readers listed in Section 1.1 will be prepared to use the book in this way. There is no dobt that for example teachers of English and possibly also EFL/ESL materials writers and studious learners and users of English may want to spend the time and effort it requires to read the book from cover to cover in order to satisfy a need for a global overview of prepositional meaning in English, but it is doubtful whether trainee translators and interpreters and undergraduates in English linguistics programs will do so. Such groups of users will probably rather want to gain access to a specific meaning of for example the preposition 'to' in order to satisfy a need for 'punctual' information in connection with for example some communicative task. We may also imagine situations in which teachers of English and EFL/ ESL materials writers may have such punctual information needs. In such cases the reader needs to consult the index. For 'to', the index has the following to say:

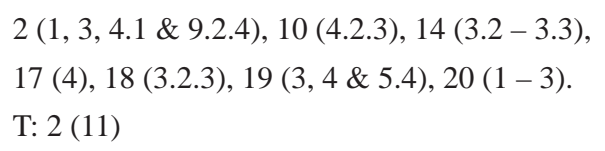


In fact, there is here a reference to all the data concerning the meanings of the preposition 'to', but no specific indication of what meanings are treated in the individual chapters, with the exception of T:2(11), where T stands for "with Landmarks of time" (p. 271). A user of the book with such kinds of 'punctual' needs would have to start his/her search for the relevant data with for example chapter 2 and then search through the relevant chapters until he/she finds what he/she was looking for. For this reason, the book is not very well suited for the satisfation of such kinds of information needs.

\section{Conclusion}

Notwithstanding the reservations made with respect to a number of notions introduced in Chapter 1 and the problems with the usefulness of the book for some of the intended readership, Lindstromberg's book is an excellent thorough and coherent account of prepositional meaning in English. Readers who approach the book in the way in which the author presumably intended it to be approached, will be rewarded with a profound global insight into not only the meanings and usages of the most frequent prepositions in English, but aslo with means to unlock the meaning(s) of English idioms in which prepositions occur.

\section{Bibliography}

Darwin, Clayton M./Gray, Loretta S. 1999. Going After the Phrasal Verb: An Alternative Approach to Classification. In TESOL QUARTERLY 33 (1), 65-83.

Leech, Geoffrey/Svartvik, Jan 2002: A Communicative Grammar of English. $3^{\text {rd }}$ ed. London: Longman.

Quirk, Randolph/Greenbaum, Sidney/Leech, Geoffrey/Svartvik, Jan 1985: A Comprehensive Grammar of the English Language. London and New York: Longman.

Schwarz, Helge 2007: Dansk-engelsk ordbog over præpositioner. København: Handelshøjskolens Forlag.

Birger Andersen 